\title{
An Analysis of Chinese Acquisitions of Made in Italy Firms in the Luxury Sector*
}

\author{
Alessandra Vecchi \\ University of Bologna, Bologna, Italy \\ Louis Brennan \\ Triniy College Dublin, Dublin, Ireland
}

\begin{abstract}
Outward Foreign Direct Investment (OFDI) from emerging economies has begun to increase significantly and has been growing at a faster pace than Foreign Direct Investment (FDI) from the developed world. This research seeks to assess the impact of Chinese acquisitions and their implications for the "Made in Italy" luxury sector and its firms. This paper presents a cross-case analysis of two Chinese acquisitions in order to provide some in-depth insights into the influences and the motives driving Chinese firms to invest in the luxury Made in Italy sector, the patterns and modes of the Chinese acquisitions as well as the competitive strategies and the distinctive challenges that both investors and acquired firms have to face. From the findings, it emerges that both the investor and the acquired firm need to overcome several key challenges to be mutual benefits from the acquisition.
\end{abstract}

Keywords: Chinese acquisitions, Made in Italy, luxury sector

\section{Introduction}

While traditionally Foreign Direct Investment (FDI) has flowed from the advanced developed economies into developed and developing countries, more recently, a new trend has emerged in the pattern of FDI. Outward FDI (OFDI) from emerging economies has begun to increase significantly and has been growing at a faster pace than FDI from the advanced developed world. Increasingly nowadays Multinational Corporations (MNCs) from Newly Industrialised Countries (NICs) are buying business assets and capabilities in the luxury sector all over Europe. Italy has a traditional competitive advantage in the production of luxury products (Vecchi, 2008, 2013). The Italian luxury market has been long been regarded as the origin of mainstream luxury goods and includes brands like Ferragamo, Prada, Gucci just to name a few. With a rich cultural heritage embedded within their brands, these firms have captured loyal customers and remarkable profits from all over the world. In Italy, luxury brands are deeply rooted in their design, quality, artisanship, and service and it has often taken decades to build their reputation. These features often appeal to those who want to instantly build a luxury brand such as the Chinese investors.

\footnotetext{
* This research was supported by a Marie Curie FP7 Integration Grant within the 7th European Union Framework Programme. A special thank goes to a former student, LudovicaRiciputi, whose contribution has been particularly valuable for shaping the research project in its initial stage.

Alessandra Vecchi, Assistant Professor, Department of Management, University of Bologna.

Louis Brennan, Associate Professor, School of Business, Trinity College Dublin.

Correspondence concerning this article should be addressed to Alessandra Vecchi, Department of Management, University of Bologna, Bologna, Italy, Via Capo di Lucca 34, 40123. E-mail: Bolognaalessandra.vecchi@unibo.it.
} 
This paper presents a cross-case analysis based on case studies of two Chinese acquisitions to provide some in-depth insights into the influences and the motives driving Chinese firms to invest beyond their borders and in particular into the luxury "Made in Italy". Both cases explore the patterns and the modes of Chinese acquisitions as well as their competitive strategies and the distinctive challenges that both the investor and the acquired firm inevitably have to face. The paper comprises six parts: The first part is introduction part; the second part contains OFDI from emerging countries; the third part shows the methodology; the fourth part is the case study; the fifth part tells the cross-case analysis; and the final part is the conclusion.

\section{OFDI From Emerging Countries}

The Chinese acquisitions affecting the luxury Made in Italy sector are emblematic of a wider trend. Many emerging economies have benefited from a massive infusion of capital, technology, and managerial expertise from the traditional industrialized countries (Rios-Morales \& Brennan, 2010). Because of this and other factors, companies in some of these countries have amassed sufficient capital, knowledge, and know-how to invest abroad on their own. The proportion of FDI accounted for by NICs is increasing. A variety of reasons has been offered for the emergence of FDI from NICs (Rios-Morales \& Brennan, 2010). These include the support of exports, the expansion of market presence, the acquisition of established brands and foreign skills, and the establishment and strengthening of local distribution networks. The increasing financial strength and the growing international exposure of companies from NICs together with greater domestic competition have also been suggested as explanations. Finally, the goals of building international brands, accessing advanced technologies, and establishing R\&D centres in developed countries help to explain this growing trend.

The surge of FDI in recent years has generated a growing body of literature on FDI with the theory of internationalisation and the eclectic paradigm widely utilized. The theory affirms that the extent and pattern of international production undertaken by MNCs are determined by the interaction of three sets of interdependent variables: ownership, localization, and internalization advantages, resulting in the abbreviation and alternative name of the eclectic paradigm, namely the OLI paradigm (Dunning, 2006). The first competitive advantage represents the ownership $(\mathrm{O})$ of specific resources to be exploited externally. The second element of the OLI paradigm regards the host country location attractiveness (L). Rugman (1981) defined the L-advantage as the Country Specific Advantage (CSA) that is unique to the business in each country. With regard to the last variable of the paradigm, the internalization (I) advantages involve the opportunity to keep firm specific resources within the company rather than to exploit them in the market through arm's length transactions (Amighini, Rabellotti, \& Sanfilippo, 2010). The OLI variables explain why internationalization occurs but do not identify the process of internationalization. Thus, the eclectic paradigm has been subsequently extended to include the theory of the Investment Development Path (IDP) that was first put forward in 1975 and since then it has gone through various iterations (Dunning, 1981, 2006; Dunning \& Narula, 1996). According to this theory, companies engage in FDI not only to exploit their existing O-advantage in a host location, but also to augment the advantages by acquiring complementary assets or new markets (Dunning, 2006). Both theories identify the institutional environment as one key factors for internationalization, however, the focus is generally on the recipient country only.

Differently, Mathews (2002) has developed a theoretical framework called Linkage, Leverage, and Learning (LLL) to analyze the phenomenon of the MNEs from the Asia-Pacific region-the "Dragon multinationals". The framework captures the idea that latecomers use their oversea investments and global linkages to leverage cost, and learn about new sources of competitive gains. Differently from the OLI 
perspective, Mathews sees the first phase of MNEs formation as most likely to begin with asset-exploring purposes rather than asset-exploiting motives. He argues that linking with mature market MNCs, a latecomer firm may leverage knowledge, technology, and market access with the result of entering in a learning process, which can be then exploited for further growth (Mathews, 2006). According to the LLL model, the degree of international success is therefore related to the extent to which links can be established and resources can be leveraged. The potential advantage is related to the accessibility to these resources in terms of their inimitability, transferability, or substitutability. The benefits depend both on the ability of the firms to leverage external resources and on their "absorptive capacity" that is their ability to identify, assimilate, and exploit external knowledge (Cohen \& Levinthal, 1990). Overall, while the conventional theories of internationalisation such as the OLI Paradigm, IDP as well as LLL offer some insights into the changing trends in FDI, they provide an incomplete understanding of the strategic drivers characterising this new phenomenon.

\section{OFDI From China}

In the context of MNCs from NICs, China represents one of the leading players ranked 5th among all economies in terms of OFDI flows (UNCTAD, 2011). While China's dominant position as a recipient of global FDI flows has been well documented, the oversea investment activities of Chinese companies have received considerably less attention. However, a recent wave of cross-border acquisitions by Chinese firms has brought increased interest to this topic. In this age of financial crisis and austerity, an increasing number of European luxury companies are seeking financial support and alliances with wealthy companies. The result is that Europe is experiencing a structural wave of Chinese MNCs acquisitions where annual inflows tripled from 2006 to 2009, and tripled again by 2011 to $€ 10$ billion for 2012 (Rhodium Group, 2012). Rui and Yip (2008) suggested that Chinese firms strategically use cross-border acquisitions to achieve goals, such as acquiring strategic capabilities to offset their competitive disadvantages and leveraging their unique ownership advantages, while making use of institutional incentives and minimizing institutional constraints. Child and Rodriguez (2005) examined the patterns of, and motives for, internationalization by prominent market-seeking Chinese firms. Case studies of these firms indicate that they are seeking technological and brand assets to create a competitive position in international markets. While mainstream theory tends to assume that firms internationalize to exploit competitive advantages, Chinese firms are generally making such investments in order to address competitive disadvantages. Fortanier and Van Tulder (2008) compared the pattern of international expansion of large firms from China with those from developed countries. They find that Chinese firms have internationalised more rapidly and more recently and tend to present a more volatile trajectory of internationalization vis-à-vis those in developed countries.

\section{Chinese Acquisitions in the "Made in Italy" Sector}

The scenario of Italy and China is particularly interesting due to the peculiarity of the Italian economic system which shares some features with the Chinese one. These are namely the strong presence of Small and Medium-sized Enterprises (SMEs) that are specialized in traditional industries (Rabellotti \& Sanfilippo, 2008; Amighini et al., 2010). A recent study (Pietrobelli, Rabellotti, \& Sanfilippo, 2010) shows that Chinese firms often regard Italy as a particularly informative European market since the consumers' taste is often regarded as a very demanding and very sophisticated. Moreover, in mainland China, Italy's reputation for high quality and prestige products remains strong and the market for luxury goods has experienced remarkable growth (The 
Economist, 2012). According to Filippov and Saebi (2008), Chinese investments in Italy reflect the effort to enter competitive European markets and obtain access to superior technologies, know-how, and capabilities. The high level of specialization in sectors such as the automotive, textile and clothing, machinery and home appliances represents a very appealing factor for China wishing to upgrade its production and technological capabilities and build its own global champions in these industries (Mariotti \& Mutinelli, 2009).

According to a report conducted by Rhodium Group (2012), the first Chinese investment in Italy took place in 1986 when Air China opened a commercial office in Rome and until the end of the 1990s the number of investments registered was very negligible. However, since 2000 the number of Chinese acquistions in Italy has increased significantly as a confirmation of the importance of the strategic asset seeking motivation. Pietrobelli et al. (2010) affirmed that what is happening today in Italy resembles the "Marco Polo effect" that happened in China centuries ago but in the opposite direction. At that time, Marco Polo was impressed by the level of civilization achieved in China and brought back to Italy some important scientific and technological discoveries. The same is happening today, since Chinese companies seem to be interested in gaining the knowledge and the expertise developed in Italy, in particular in design-intensive and in high-quality production. For these reasons, Chinese MNEs are increasingly targeting the acquisition of technological skills, design capabilities, and brands to acquire those local competences that are available in the Italian specialized manufacturing clusters (Pietrobelli et al., 2010) as illustrated in Table 1.

Table 1

Main Acquisitions by Chinese Firms in Italy by Sector

\begin{tabular}{|c|c|c|c|c|}
\hline Year & Target & Acquirer & Sector & Stake $\%$ \\
\hline 2001 & Meneghetti & Haier & White goods & 100 \\
\hline 2004 & Wilson & Wenzhou Hazan & Textile & 90 \\
\hline 2005 & Benelli & Qianjiang Ltd & Motorbikes (luxury) & 100 \\
\hline 2006 & Elios & Feidiao Electrics & White goods & NA \\
\hline 2007 & HPM Europe Spa & Hunan Sunward Intelligent Machinery & Machinery & 51 \\
\hline 2007 & Omassrl & XynyuHengdeli Holdings & Textile & 90 \\
\hline 2008 & Cifa & Changsha Zoomlion & White goods & 60 \\
\hline 2008 & Tacchini Group & Hembling International Holdings Limited & Fashion (luxury) & 100 \\
\hline 2009 & Elba & Haier & White goods & 20 \\
\hline 2010 & Volvo Italia & Zhejiang Geely Holding & Automotive & NA \\
\hline 2011 & Sirton & Shanghai First Pharmaceuticals & Pharmaceutical & NA \\
\hline 2012 & Ferretti Group & Shandong Heavy Industries-Weichai Group & Boats (luxury) & 75 \\
\hline 2012 & De Tomaso & Hotyork Group & Automotive (luxury) & 80 \\
\hline 2012 & Miss Sixty & Crescent Hyde Park & Fashion (luxury) & 50 \\
\hline 2012 & Ferragamo & Peter Woo & Fashion (luxury) & 8 \\
\hline
\end{tabular}

Notes. NA: Not Available. Source: Data collected by the authors.

Rather than building home-grown brands that would require a long time to become established, Chinese firms seek to invest in Italian brands that possess a rich heritage but have fallen on hard times or gone out of fashion to consolidate their position in the global market. An emblematic example is the acquisition of Officina Meccanica Armando Simoni (OMAS), a company specialized in the production of luxury fountain pens since 1925, which was acquired in 2007 by the group XinyuHengdeli Holdings. Other cases are the Hembly International Holdings, a leading Asian clothing retailing group that acquired Sergio Tacchini, a well-known but declined luxury clothing brand in 2007 and Trendy International, a Hong Kong clothing distributor who recently bought a minority stake in Miss Sixty, a popular luxury clothing manufacturer for teens. Overall, the 
widespread anxiety concerning China's international expansion calls for a better understanding and knowledge of the strategies of Chinese companies entering the Italian market to better inform what is becoming an increasingly important debate. Although this topic is becoming fashionable in international business studies, the empirical evidence on Chinese FDI in European countries is quite limited and mainly relates to the UK (Burghart \& Rossi, 2009; Cross \& Voss, 2008; Liu \& Tian, 2008) and Germany (Schuller \& Turner, 2005). This evidence is even scarcer if we consider Italy and to large extent the luxury sector. As such, there is a valuable opportunity to conduct further research.

\section{Methodology}

This paper presents the results of two case studies of Chinese acquisitions that were conducted to provide some in-depth insights into the influences and the motives driving these firms to invest into the luxury Made in Italy. The paper relies on two in-depth case studies (Yin, 2008) that were purposefully chosen to illustrate some distinctive organizational challenges that were faced by both the target and the acquirer firms before, during and after the acquisition. The acquisitions of Benelliby Qianjiang Ltd and of OMAS by XinyuHengdeli Ltd were selected as suitable case studies. Both luxury firms were acquired by Chinese investors in 2005 and in 2007 respectively. Both Italian firms operate in a niche luxury sector and they both enjoy a long history and tradition and can be considered as being representative of the luxury Made in Italy due to their design-intensive nature and the premium quality of their products.

To increase comparability and by thus enhancing the rigour of the findings, the two case studies followed a very structured research protocol as illustrated in Table 2. Apart from secondary research in the form of media reports and company documentation, primary research was carried out via interviews. These in depth interviews were with conducted with two top executives, namely, the Italian chief financial officer (CFO) of the Benelli and the Chinese Chief Executive Officer (CEO) of OMAS and with a range of other key informants.

Table 2

Case Study Research Protocol

\begin{tabular}{|l|l|l|}
\hline Data source & Main focus \\
\hline $\begin{array}{l}\text { In-depth interview with the company } \\
\text { Italian CFO (Benelli) }\end{array}$ & Overview of the target's market & Overview of the acquirer's market \\
\cline { 2 - 3 } In-depth interview with the company & Brief history of the target & Brief history of the acquirer \\
\cline { 2 - 3 } Chinese CEO (OMAS) & Target's main strategic assets & Acquirer's main strategic assets \\
\cline { 2 - 3 } & The acquisition & Acquirer's international expansion \\
\cline { 2 - 3 } & The post-acquisition \\
\cline { 2 - 3 } & The integration phase \\
\hline In-depth interviews with key-informants & Discussion of the findings to increase their robustness \\
\hline
\end{tabular}

Firstly, the Italian CFO and the Chinese CEO were interviewed to investigate some aspects of the acquisition that would not have emerged with other data collection methods. Both have been working in their respective companies for many years and played an extensive role before, during and after the acquisition. The interviewees also provided useful material such as the financial company reports along with secondary data that were useful to corroborate the findings. Additionally, to overcome the limitations that conducting two purposefully chosen case studies entails (Yin, 1984), six key informants possessing some relevant expertise in the field were also interviewed to further increase the robustness of the findings (Tellis, 1997). 


\section{The Case Study: The Acquisition of Benelly by Qianjiang Ltd}

The target. Benelli is one of the most important Italian manufacturers of luxury motorcycles. The company has been established in Pesaro in 1911 and is currently the oldest of all European motorcycle factories in operation. The company has been always family-run and has a very interesting history, having survived both World War I and World War II. It did very well until the 1960s when it entered a profound crisis due to the arrival of Japanese manufacturers, which caused a crisis in the entire European motorcycle industry. In 1995 it was initially bought by the Indesit Group that attempted to relaunch it. Despite this effort, the need for sizeable investments and the enormous financial difficulties led the company into liquidation. Following an intense period of negotiations, in 2005 Benelli was acquired by Qianjiang Ltd (QJ).

The acquirer. QJ is a large-scale state-owned group producing motorcycles, and one of the 520 state enterprises certified by the Chinese State Council, which focuses on the low price segment of the market and has several typical Chinese-style low-power motorcycles (MOFCOM, 2011). The company is "dedicated to a combination of European design, Japanese quality and Chinese costs" (Spigarelli et al., 2012). The QJ Group was established in 1971 as a chemical engineering machinery factory, changed its line of production to motorcycles in May 1985 and experienced low-cost expansion and growth within a short time frame. It has been listed on the Shenzhen Stock Exchange since 1999. Only 20 percent of its production is sold abroad to markets in 110 countries. While the majority of its production tends to be low cost, the company targets the high-end segment of the market in the EU and the USA by devoting more attention to technology, brand, quality, and service. QJ has accumulated a great wealth of rich experience in product development via the building of long term collaborations with R\&D centres, leading institutes and world class experts. The Group has an exemplary quality management system (ISO9001, CE, GS, CSA, and UL standards) and has received quality licenses from national import and export product testing bureaus. QJ over the years has been engaged in many partnerships in order to upgrade its products. Currently, QJ owns two domestic brands (Cozily and Qianjiang) and three European brands (the Italian Benelli, the HungarianKeeway and a generic brand stemming from a partnership with AC, an Austrian company). With these three leading European brands, the company plans to build and expand its markets in Europe and North America, to accelerate technical innovations and to establish itself in a more competitive position in the international market (Spigarelli et al., 2012).

The acquisition. QJ approached Benelli for the first time in 2005. Benelli, which at the time was looking for an injection of capital, decided to sign an agreement that would help it overcome its financial constraints and at the same time benefit from QJ's main strengths, namely, its high-efficiency plants and low production costs (CFO interview). On September 16th, 2005, a deal was reached and Benelli QJ was founded. QJ acquired BenelliS.r.1. for a total of EUR 59.7 millions including the assumption of EUR 52.7 millions of debt (Benelli financial statement, 2006). QJ decided to revitalize the company by implementing a very pragmatic industrial plan by keeping the localisation of the firm in Pesaro and by keeping the entire workforce previously working in the company. Only a few staff from China were expatriated to Pesaro, these are namely the sales director, the quality manager, and the managing director. All of the technicians, workers, and engineers are Italian. An important choice made at the time by QJ was to nominate the previous CTO as the vice managing director. He was considered the "historical heart and soul of the company" (CFO interview) but he left the company in 2009, after repeated conflicts with the new managing director. All the operations related to administration, production and R\&D have been maintained in Pesaro. As pointed out by the CFO and by several interviewees, the strategic objective 
of the acquisition was to leverage the recognized brand, the heritage along with the knowledge of the luxury segment to penetrate a new high-premium market segment for QJ by delivering high-quality production output.

Having become aware that with two brands born from nothing they cannot produce motorcycles, QJ decided to buy Benelli so to have the technology and design and a respected brand in Europe. Essentially, they bought the history and the know-how. (Benelli's former CTO interview)

Further, the QJ objective was also to use Benelli's know-how in China to increase the quality of its domestically manufactured products and to diversify its production to target a new segment. The rationale behind the acquisition was to acquire an innovative technology to more effectively counteract the fierce competition from the Japanese manufacturers in China (Benelli's former CTO interview).

The post-acquisition. The first initiative after the acquisition was to bring the whole production of the engines in-house, within Benelli, whereas before the engine was developed in-house and the production was outsourced. According to the Chinese management, the decision to outsource the engines had been a remarkable mistake that resulted in high production costs, quality defects and ultimately leading to some inefficiency in the engines' performance (CFO interview). Now Benelli is equipped with a production line that produces 70 engines per day. This has been coupled with a significant increase of the workforce that grew from 45 to 90 employees. To this purpose, QJ signed an agreement with a local professional school involving student placements and apprenticeships. The existing suppliers were also all maintained. The technical department of Benelli QJ works closely with QJ technical department so as to capitalise on their existing potential synergies. Benelli QJ technical department in Pesaro is in charge of the design of the product, then the prototypes are sent to QJ technical department in China that is responsible jointly with the Italian division for its subsequent industrial development. Once the industrial development has been completed, the actual production takes place in Italy. The other important initiative implemented by QJ has been to significantly reduce both the production costs and the sales costs. Benelli QJ has started producing a number of secondary components in China.

We started from the simplest types of plastics components, wirings and electrical controls mounted on the handlebars. A visible shift towards cost reduction, but without affecting the quality, because the parts that require more advanced processing are still produced in Pesaro. (CFO, interview)

As a result, Benelli QJ produces in China the gear-box, the throttle-body system, and balancing-shaft. "There are Italian technicians who are often in China so to support them in the production as well as in the quality control of the components"- the CFO added. "The head office often asks to borrow moulds, Italian technicians, or our engineers. Their presence is often required in China and this is a clear sign that their objective is to learn some critical phases of the production process" (CFO's interview). As for reducing the sales costs, the Italian commercial network relies on official dealers. The international distribution network is based on joint subsidiaries with Benelli and Keeway products, both brands are sold through the same distribution network but differentiated by price and quality. Overall, Benelli QJ relies on a new method of work that capitalises on the existing synergies between the two companies by leveraging their mutual strengths in order to exploit their complementarities. Benelli's motorcycling tradition, the Italian cutting-edge technology in the production of the engine and its distinctive design capabilities combined with QJ's production efficiency have resulted in new valuable opportunities for Benelli QJ to develop and introduce new models to the market. Seven new models were manufactured in the three years following the acquisition.

The integration phase. After the acquisition, however some issues between QJ and Benelli emerged. In 
particular, cultural differences emerged in terms of staff behaviour and very different management styles.

It is very difficult to understand the behaviour of a Chinese person. For a long period, we were not able to understand why they did not give us certain answers and we wondered if it was because they could not or they did not know. After some months, we understood that they were not interested in sharing some information with us. (CFO interview)

Issues related to different mind-sets, habits and also familiarity with different work environments in Italy and China soon arose in the daily routines. Communication has been a key issue, especially in the technical area. As a result of language barriers and difficulties associated with different working practices, many important projects were delayed. During the interview, the CFO for instance explained that the Italian employees were puzzled by the Chinese staff falling asleep after lunch as they were in need of a nap. This would undermine their professional credibility. Similarly the Chinese managers did not see the problem of calling to work the Italian employees on Sundays. According to the CFO, these problems stemming from mutual cross-cultural misunderstanding have significantly hindered the company's potential. Another critical issue concerned the peculiarity of the Chinese management style characterised by a great focus on efficiency. In its attempt to reduce costs QJ had to mostly cut all those investments that were characterised by less tangible returns. This rationalisation strategy resulted in reduced investment in sales promotion, marketing, and post-sales assistance without concomitantly improving the worldwide strength of the brand and the efficiency of the international distribution network. Additionally, issues emerged from the highly hierarchic approach of the Chinese management.

Each decision should be discussed with the MD and this makes us stuck and the processes arevery slow. When the MD is abroad and we have to deal with urgent situations we get stuck because we cannot move without any authorization. They do not delegate anything. (CFO interview)

Another issue emerged by which after a first "enthusiastic phase", human relations became somehow complicated. This was well explained by the CFO when discussing the reasons that led Mister Marconi (former CTO and then VP under QJ management) to leave Benelli in 2009.

At first, the Chinese management mainly aimed to keep Marconi, they stated that he was the heart and soul of the firm but then the management wanted to be more and more involved in any proposal of change and Marconi, missing his autonomy and his discretional power, decided to leave the firm in 2009. (CFO interview)

Yet, "All the planning and control activities were mono directional" commented the interviewee. Benelli QJ does not receive any information on the strategic development plans from the QJ group or any formal and periodical feedback on its results and performances. Yet, the companies' databases are not integrated since only QJ can access Benelli's information system. Overall, "it seems that they consider us as a pawn controlled by a world industrial giant" (CFO interview). Table 3 summarises the acquisition of Benelli by QJ and its critical phases.

Table 3

The Acquisition of Benelli and Its Critical Phases

\begin{tabular}{|l|l|}
\hline The acquisition & $\begin{array}{l}\text { The strategic objective of the acquisition was to leverage the recognized brand, the heritage along with } \\
\text { the knowledge of the luxury segment to penetrate a new high-premium market segment for QJ by } \\
\text { delivering high-quality production output. } \\
\text { Further, the QJ objective was also to use Benelli's know-how in China to increase the quality of its } \\
\text { domestically manufactured products and to diversify its production to target a new segment. } \\
\text { The rationale behind the acquisition was to acquire an innovative technology to more effectively } \\
\text { counteract the fierce competition from the Japanese manufacturers in China. }\end{array}$ \\
\hline
\end{tabular}


(Table 3 continued)

\begin{tabular}{|l|l|}
\hline The post-acquisition & $\begin{array}{l}\text { QJ decided to revitalize the company by implementing a very pragmatic industrial plan by keeping the } \\
\text { localisation of the firm in Pesaro and by keeping the entire workforce previously working in the company. } \\
\text { The first initiative after the acquisition was to bring the whole production of the engines in-house, within } \\
\text { Benelli, whereas before the engine was developed in-house and the production was outsourced. This has } \\
\text { been coupled with a significant increase of the workforce that grew from 45 to } 90 \text { employees. The } \\
\text { existing suppliers were also all maintained. The technical department of Benelli QJ works closely with QJ } \\
\text { technical department. Benelli QJ technical department in Pesaro is in charge of the design of the product, } \\
\text { then the prototypes are sent to QJ technical department in China that is responsible jointly with the Italian } \\
\text { division for its subsequent industrial development. Once the industrial development has been completed, } \\
\text { the actual production takes place in Italy. } \\
\text { The other important initiative implemented by QJ has been to significantly reduce the sales costs by } \\
\text { restructuring Benelli's distribution channels. } \\
\text { Benelli's motorcycling tradition, the Italian cutting-edge technology in the production of the engine and } \\
\text { its distinctive design capabilities combined with QJ's production efficiency have resulted in new valuable } \\
\text { opportunities for Benelli QJ to develop and introduce new models to the market. }\end{array}$ \\
\hline The integration phase \\
$\begin{array}{l}\text { Cultural differences emerged in terms of staff behaviour and very different management styles. } \\
\text { Issues related to different mind-sets, habits and also familiarity with different work environments in Italy } \\
\text { and China soon arose in the daily routines. } \\
\text { Communication has been a key issue, especially in the technical area. As a result of language barriers and } \\
\text { difficulties associated with different working practices, many important projects were delayed. } \\
\text { Another critical issue concerned the peculiarity of the Chinese management style characterised by a great focus } \\
\text { on efficiency. Additionally, issues emerged from the highly hierarchic approach of the Chinese management. }\end{array}$ \\
\hline
\end{tabular}

\section{The Case Study: The Acquisition of OMAS by XinyuHengdeli Holding Ltd}

The target. OMAS is one of the most important Italian luxury fountain-pen manufacturers. The company was founded by Armando Simoni in 1925 and has a very rich history and its products are entirely manufactured in their factory located in Bologna, Italy. While the company started as a small workshop it has grown into an internationally recognized pen company. Armando was a skilled technician with strong interest in Greek culture. The founder was nominated Cavalieredella Corona d'Italia - Knight of the Italian Crown —and the noble status of Simoni was extended to his firm as the company soon became an important player in its market due to its rich history and soon developed a strong international presence with about $75 \%$ of its revenues outside of Italy. However, OMAS remained a family business. After the founder's death in 1958, his daughter, Raffaella and her husband, Angelo Malaguti took over the leadership of the company. In 1983, their son Gianluca continued in the role. In May 2000, OMAS became part of the LVMH Group (Moët Hennessy Louis Vuitton), that was able to recognize in OMAS a great know-how and underdeveloped potential (LVMH website). This partnership allows OMAS access to the benefits of the large commercial network of LVMH Group while maintaining its operations in Bologna. In 2007, XinyuHengdeli Holdings Limited (XHH), luxury watch distribution and retailer in Asia and strategic partner of LVMH Watches \& Jewellery Division announced the acquisition of a $90.1 \%$ equity stake in OMAS.

The acquirer. XHH founded in Beijing in 1957, is the world's largest watch retailer of internationally renowned brands. The company operates in two segments: the retail segment, which entails retail business in Mainland China, Taiwan, and Hong Kong; and the wholesale segment, which distributes numerous world renowned brand watches in Mainland China and Hong Kong. XHH has been listed on the Main Board of the Hong Kong Stock Exchange since 2005. Hengdeli Group employs a total of 7,015 employees in Mainland China, Hong Kong, and Taiwan. The group's core business is the retail of middle-to high-end internationally renowned watch brands and it primarily focuses on the building-up of its retail network in the Greater China region with a core presence in Mainland China. With internationally renowned watches serving as a core focus, 
the retail of a portfolio comprising middle-to-high-end products, such as jewellery, leather goods, and writing instruments, remains the strategic direction of the group. XHH has an extensive sales network of 428 retail outlets in Mainland China, Hong Kong, Taiwan, and Macau, through which it distributes over 50 internationally renowned watch brands (Hengdeli Group interim report, 2012). The group is engaged in the distribution of numerous internationally watch brands on both exclusive and non-exclusive basis. Across its entire wholesale business, XHH serves approximately 400 wholesale customers in nearly 100 major cities. The group distributes over 50 internationally renowned brands. XHH has developed a comprehensive network of retail outlets in Mainland China, with heavy presence in key regions including Shanghai, Beijing, Northeast China, Zhejiang, Jiangsu, Henan, Shanxi, and Hubei, which facilitated the consolidation of its market share. Meanwhile, the group is also strengthening its retail network by expanding into Southwest and Central China. The retail business of the group in Taiwan is currently in the network-building stage while it operates a total of 15 retail outlets located in prime districts in Hong Kong.

The acquisition. On October 28th, 2007, XHH acquired 90.1\% equity stake in OMAS from the LVHM Group with whom it has a strategic partnership. The remaining $9.9 \%$ stake in OMAS is still held by LVMH Group.

The opportunity of acquiring OMAS comes from the proposal of the LVHM group which had been our partner since a long time. The group decided to seize this opportunity by having a clear purpose: to enter the domestic market by leveraging on the prestige of the Made in Italy brand. Thus, we have decided to invest in its creativity, design and brand power. (Interview with the OMAS CEO)

The acquisition is in line with the group business expansion in the sector of luxury consumer goods. The rationale for the acquisition has been twofold. First, XHH sought the acquisitions of Italian luxury brands in order to diversify their core business, namely, the distribution of European watch luxury brands in the Chinese market. Second, XHH wished to acquire a better understanding of the know-how in both production and brand marketing in order to increase XHH's market share in China by taking advantage of the great market potential. OMAS was one of the very first luxury brands they bought in Europe and having a very traditional brand like OMAS in their portfolio the group can better understand the strategy of other European luxury brands.

The post-acquisition. "The aim I had once I become OMAS CEO was to restore the organizational and operational structure of the company that led OMAS underperforming despite of its great potential" (Interview with OMAS CEO). According to the CEO, this improved performance comes from a better management both of the short-term liquidity and of the post-sales service. XHH is a leader in the distribution of luxury goods, but it has no experience in the manufacturing sector. The Chinese MNEs has therefore decided to maintain the Italian production in Bologna recognizing that the value of OMAS lies in its handcraft products coming from a long tradition and know-how "Our market positioning is a niche one, so we have to offer high quality standards and those can be assured only by maintaining the Italy based production with the historical Italian technicians team" (Interview with OMAS CEO). Moreover, after the acquisition, many suppliers have ended their relationship with OMAS since they feared the fact that the Chinese group could move the production to China thus decreasing the quality and the prestige of its products. Therefore, the Chinese management did not want to nourish this thinking. For the same reason no Chinese technicians were hired. As a result, OMAS production was kept in Bologna and the company has kept the Italian technical team in his current capacity in order to transmit an authentic image of Made in Italy which justifies the higher prices of its products in China. This has allowed the firm to increase its control over its supply chain giving OMAS a higher degree of flexibility. 
Before the acquisition, one of the main difficulties faced by OMAS was to collect the account receivables (OMAS financial statements 2002-2012). LVHM strategy was to push for high volume sales by often granting long deferred payments. As a result, this strategy led to high demands for cash forcing the company to increasingly rely on financial debt (OMAS financial statements 2002-2012). After the acquisition, in order to solve this issue, a "no payment, no shipment" strict policy has been adopted. Another objective of the new Chinese management has been to revive the relationship with and reacquire an image of reliability with former customers that previously faced inefficiencies linked to the post-sale assistance service. Accordingly, a great part of investments were aimed to improve the customer service- "Our product is a luxury one and, in order to create a customer loyalty marketing, it is fundamental to offer an efficient and reactive service. We aim at three objectives in this service: speed, higher standards, satisfaction" (Interview with OMAS CEO). For this reason, a new internal policy states that within 12 hours of a customer enquiry, the OMAS team has to email back the customer with a detailed analysis of the problems and the costs and time for fixing. "I could summarize the new business approach in two words: standardization and continuity" (Interview with OMAS CEO). As far as the standardization of processes concerned, the CEO has implemented a strict internal regulation regarding working hours and working procedures aimed at a proper cost control while further developing the company's production facilities. The second point is related to the vision and strategy of the company. "I think it is fundamental to always bear in mind the direction and follow it. I expect that once given the rules, there will be a total continuity, consistency and consolidation" asserted OMAS CEO. Therefore, the managerial structure of the company was significantly reduced. The complete sales team of OMAS decided to leave the company as they were unconvinced about the changes implemented by the new management. They complained that the process was managed from top down and about the fact that the team was left unclear about the strategy in the first few months. While the new XHH management team blamed the OMAS sales team for the unsound financial situation of the company. As a result of this issue, the first few months after the acquisition were characterized by mutual mistrust and criticism. Finally, a lot of inside knowledge and reputation was lost when the former Vice-President and nephew of the OMAS founder decided to step out of the company. Managers in marketing, sales, operations, and purchase management were reduced from 11 to four. According to the CEO, by centralizing all the activities in the same position the aim was to increase the efficiency and the effectiveness of the management, the promotion of a more cohesive team spirit and increase the productivity. A strict monitoring system has been implemented through several dedicated meetings that take place weekly in OMAS. The CEO aim is to continuously motivate, control, and correct his team in order to better allow them to follow the company's strategic vision. To this purpose, training programs and several dedicated meetings were introduced in order to align employees' expectations with the company strategic vision.

The integration phase. During the integration process many difficulties were faced by the new Chinese management. "In the Italian system, the main problem is the bureaucracy. Too many procedures and too long waiting times" (Interview with OMAS CEO). The Italian legislative and bureaucratic system often discourages Chinese investors. Moreover, the Chinese CEO stressed the fact that the Government does not give any incentive or support to balance such a complex system - "It does nothing for make foreign companies comfortable to invest here. No English, no service, no support" (Interview with OMAS CEO). Another main obstacle is represented by the high taxation. Yet, to provide another example of inefficiency the CEO explained that he has to wait more than a year to get his Visa and that when he finally obtained his Visa and went to collect it the employee threw to him- "Things like these would never happen in other countries" commented by the CEO. 
Due to such difficulties the CEO explained that many times he thought of moving the production to countries like Slovenia that offer great incentives and to maintain, in Italy, just the R\&D, the choice of style and design, a warehouse, a marketing office and to change the label from "made in Italy" to "designed in Italy". According to the $\mathrm{CEO}$, this approach is necessitated by the high degree of discretion of some informal conventions adopted by the firm prior to the acquisition and that often caused technical problems. For this reason, the Chinese management has implemented a strict set of formal rules to standardise the work procedures:

OMAS has a 85 year-history and also people working inside this firm have their habits and want to keep doing what they were used to. However, everyone has to start and finish work at the same time. We are a team and if there is some delays everyone will have pay for it. (Interview with OMAS CEO)

To explain the Chinese management approach the CEO used the metaphor of the boat and the skipper.

As CEO I am the skipper who chooses the direction. The sailors are the employees who have the task to give me the right information and I give them the guidelines. They should trust me and follow me. I do not have time to hear their complaints. Those who do not share my idea can get off the boat. (Interview with OMAS CEO)

Yet, the CEO stressed the importance to have a highly hierarchical structure since each employee has to be afraid of the boss as this is the only way to increase efficiency. "A good manager has to know how to share the tasks with the right people, control them and give them the right direction but the confidence is gained in time only by the achievement of some positive results" (Interview with OMAS CEO). Table 4 summarises the acquisition of OMAS by XHH and its critical phases.

Table 4

The Acquisition of OMAS and Its Critical Phases

\begin{tabular}{|c|c|}
\hline The acquisition & $\begin{array}{l}\text { The rationale for the acquisition has been twofold. First, XHH sought the acquisitions of Italian luxury } \\
\text { brands in order to diversify their core business, namely, the distribution of European watch luxury } \\
\text { brands in the Chinese market. Second, XHH wished to acquire a better understanding of the know-how } \\
\text { in both production and brand marketing in order to increase XHH's market share in China by taking } \\
\text { advantage of the great market potential. OMAS was one of the very first luxury brands they bought in } \\
\text { Europe and having a very traditional brand like OMAS in their portfolio the group can better } \\
\text { understand the strategy of other European luxury brands. }\end{array}$ \\
\hline The post-acquisition & $\begin{array}{l}\text { The aim was to restore the organizational and operational structure of the company that led OMAS } \\
\text { under performing despite of its great potential. This improved performance comes from a better } \\
\text { management both of the short-term liquidity and of the post-sales service. } \\
\text { XHH decided to maintain the Italian production in Bologna recognizing that the value of OMAS lies in } \\
\text { its handcraft products coming from a long tradition and know-how.No Chinese technicians were hired. } \\
\text { OMAS production was kept in Bologna and the company has kept the Italian technical team in order to } \\
\text { transmit an authentic image of Made in Italy which justifies the higher prices of its products in China. } \\
\text { After the acquisition a "no payment, no shipment" strict policy has been adopted. } \\
\text { Another objective of the new Chinese management has been to revive the relationship with, and to } \\
\text { reacquire an image of reliability with former customers that previously faced inefficiencies linked to the } \\
\text { post-sale assistance service. Accordingly, a great part of investments were aimed to improve the } \\
\text { customer service. } \\
\text { As far as the standardization of processes concerned, the CEO has implemented a strict internal } \\
\text { regulation regarding working hours and working procedures aimed at a proper cost control while further } \\
\text { developing the company's production facilities. } \\
\text { A further point is related to the vision and strategy of the company. The managerial structure of the } \\
\text { company was significantly reduced. By centralizing all the activities in the same position the aim was to } \\
\text { increase the efficiency and the effectiveness of the management, the promotion of a more cohesive team } \\
\text { spirit and increase the productivity. Training programs and several dedicated meetings were introduced } \\
\text { in order to align employees' expectations with the company strategic vision. } \\
\text { Lastly, it can be noted that there was a major exodus of employees from the firm including some key } \\
\text { personnel. }\end{array}$ \\
\hline
\end{tabular}


(Table 4 continued)

\begin{tabular}{|l|l|}
\hline The integration phase & $\begin{array}{l}\text { During the integration process many difficulties were faced by the new Chinese management as the } \\
\text { Italian legislative and bureaucratic system often discourages Chinese investors. Another main obstacle } \\
\text { is represented by the high taxation. } \\
\text { The Chinese management has implemented a strict set of informal rules to standardise the work procedures } \\
\text { and to foster team spirit but at the same time by adopting a highly hierarchical structure to increase efficiency. }\end{array}$ \\
\hline
\end{tabular}

\section{Cross-Case Analysis}

The Benelli and OMAS case studies attempt to provide evidence regarding the multi-faceted path and drivers behind the internalization process of Chinese MNEs and investigate how the integration process between Chinese and Italian management occurs. Both the acquisitions are the result of a clear strategy: purchasing Italian prestigious brands as a shortcut to acquire a brand's heritage, and thanks to the injection of financial resources to re-launch the production to dominate both the European and Chinese markets. However, the deals are expression of two different phases of the internationalization process of Chinese MNEs. Benelli, acquired in 2005, is the example of the export-oriented approach that China adopted in the pre-crisis period aimed at dominating European markets playing on the historic brand well-known in this sector. While OMAS, acquired in 2007, represents a new phase in the Chinese internalization process: the domestic-oriented one. Since the European markets are not as attractive as they were before the crisis, Chinese MNEs are now trying to exploit the great potential represented by the domestic market, especially in the luxury sector. Both Benelli and OMAS were facing a financial crisis at the moment of the acquisition and they needed liquidity, and this favoured the Chinese acquisitions. Chinese firms, beyond capitalising on the value of the Italian brands, tried also to benefit from a well-developed network of contacts and from the know-how stemming from the companies' long tradition in their sector. Both Chinese investors took advantage of the international reputation of the Made in Italy brands to enter new distribution channels. As for Benelli, QJ leveraged the synergies between the Chinese labour costs and the Italian technology and style to produce at lower production costs while attaining a higher market positioning and thus higher margins. In the OMAS case, XHH took advantage both from its leadership as a distributor in the domestic market and from the prestige recognized by Chinese in Made in Italy brands to enhance the sales portfolio and to pave the way for the long-term brand development. Both products (Benelli's motorcycles and OMAS' fountain pens) rely on a specific know-how that is linked to the Italian design tradition and style. QJ, by acquiring Benelli, has largely benefited from its R\&D activities and thanks to the continuous collaboration between Chinese and Italian technicians has acquired proficiency of new technologies and of work methods. By acquiring OMAS, XHH acquired a prestigious brand allowing the company to widen its own portfolio of products supporting its geographical expansion and its access to strategic distribution centers in the domestic market. Moreover, XHH expands its customer base thanks to the appetite for Made in Italy products of more and more demanding Chinese consumers. Increased market visibility and a wide range of quality products combined with innovative designs and long tradition helped XHH to better grasp the increasing potential of the Chinese luxury industry. In the case of both acquisitions, the Chinese investors have the opportunity to acquire all the tangible and intangible assets (such as the know-how and the local contacts) which otherwise would take them many years to be built them from scratch. Accordingly, in both cases the identity of the target company has been maintained by avoiding the delocalization of both the production and to some extent by maintaining the human resources. This is in line with the identification of strategic asset seeking as first motivation of the Chinese MNEs which aim to absorb the Western technical know-how and management skills. According to Rui and Yip (2008), Chinese companies strategically use acquisitions to achieve specific goals, such as acquiring 
strategic capabilities to offset their competitive weaknesses and leveraging their unique ownership advantages, while making use of institutional incentives and minimizing domestic constraints. The findings confirm that the ongoing increase of acquisitions carried out by Chinese MNEs in the luxury Made in Italy is a signal of the strategic-asset seeking motivations where the intent is to absorb new knowledge and know-how from the target company. The analysis of both acquisitions confirms that technology (as in the case of Benelli), design and the prestige of a long-established brand (as in both cases) are the main drivers. In particular, the research shows that both the acquirers sought to strengthen their competitiveness both domestically $(\mathrm{XHH})$ and on the international market (QJ) by leveraging the design and the prestige of the Made in Italy behind the brands. However in both cases, the integration has been a long and a difficult process. Different habits and cultural background emerge in daily routines due also to differing working environments in China and Italy. On the one hand, the Chinese management is frustrated by the bureaucracy that hinders the business development. On the other hand, Italian managers are hampered by a rigid and suspicious mentality and by a highly centralized decision-making management style that can create rifts between management and employees by thus delaying the implementation of the strategy. As far as the post-acquisition phase, the literature suggests that, in most cases, the acquirer follows a structural integration approach by replacing senior managers and erasing the target identity (Yamin \& Forsgren, 2006). However, the findings highlight that this approach was not followed by the acquirers. On the contrary, QJ tried to keep the target's identity by maintaining the production facilities in their original location in Pesaro and by retaining its executives, workforce, and suppliers. XHH reduced the number of executives but maintained the production facilities in Bologna as well as the technical team. This seems to be in line with the identification of strategic asset seeking as the main motivation of the Dragon multinationals (Pietrobelli et al, 2010). Table 5 summarises the main similarities and differences between the two acquisitions.

Table 5

Similarities and Differences Between the Two Acquisitions

\begin{tabular}{|c|c|}
\hline The acquisition & $\begin{array}{l}\text { Purchasing Italian prestigious brands as a shortcut to acquire a brand's heritage, and thanks to the } \\
\text { injection of financial resources to re-launch the production to dominate both the European and Chinese } \\
\text { markets. Benelli is an example of the export-oriented approach that China adopted in the pre-crisis } \\
\text { period aimed at dominating European markets. The acquisition of OMAS represents a new phase in the } \\
\text { Chinese internalization process - the domestic-oriented one. } \\
\text { Both acquirers through the acquisition wished to gain a better understanding of the know-how in both } \\
\text { production and brand marketing. Both targeted very traditional brands with a rich heritage to leverage } \\
\text { the prestige associated with having them in their portfolio and the acquisition was instrumental to better } \\
\text { understand the strategy of other European luxury brands. }\end{array}$ \\
\hline The post-acquisition & $\begin{array}{l}\text { The rationale was to restore the organizational and operational structure of both target firms that led } \\
\text { them underper forming despite of their great potential. This improved performance comes from } \\
\text { bringing the production of the engines in-house and reducing the sales costs in the case of Benelli and a } \\
\text { better management of the short-term liquidity and of the post-sales service in the case of OMAS. In } \\
\text { both cases as the result the workforce has been substantially increased. Both acquirers decided to } \\
\text { maintain the Italian production in Italy recognizing that the value of the Made in Italy production lies in } \\
\text { its handcraft products coming from a long tradition and know-how. In both cases, no Chinese } \\
\text { technicians were hired and the entire workforce previously working in the company was maintained. } \\
\text { The production was kept in Italy in order to transmit an authentic image of Made in Italy which justifies } \\
\text { the higher prices of its products in China. The existing suppliers were also all maintained. However in } \\
\text { both cases there have been departures of key personnel. } \\
\text { Chinese firms, beyond capitalising on the value of the Italian brands, tried also to benefit from a } \\
\text { well-developed network of contacts and from the know-how stemming from the companies' long } \\
\text { tradition in their sector. Both Chinese investors took advantage of the international reputation of the } \\
\text { Made in Italy brands to enter new distribution channels. } \\
\text { The managerial structure of both companies has been altered. In both cases, efficiency has been pursued } \\
\text { by introducing an higher degree of centralization to improve the effectiveness of the management. }\end{array}$ \\
\hline
\end{tabular}


(Table 5 continued)

\begin{tabular}{|l|l|}
\hline The integration phase & $\begin{array}{l}\text { In both cases, the integration has been a long and a difficult process. Different habits and cultural } \\
\text { background emerge in daily routines due also to differing working environments in China and Italy. On } \\
\text { the one hand, the Chinese management are frustrated by the bureaucracy that hinders the business } \\
\text { development. On the other hand, Italian managers are hampered by a rigid and suspicious mentality and } \\
\text { by a highly centralized decision-making management style that can create rifts between management } \\
\text { and employees by thus delaying the implementation of the strategy. }\end{array}$ \\
\hline
\end{tabular}

\section{Conclusions}

The findings on the impact of the acquisitions on the targets are in line with Hofstede's cultural distance hypothesis (1980) that suggests that the difficulties, costs, and risks associated with cross-cultural contact increase with growing cultural differences between two firms. The research thus provides additional insights by highlighting how the two different management styles might cause significant misunderstandings that created a rift between management and employees, impeding or delaying the strategy implementation. The findings thus confirm that acquisitions are difficult to implement because they require a "double layered acculturation" (Barkema, Bell, \& Pennings, 1996), whereby not only corporate cultures, but also national cultures have to be aligned. Different values, goals, and beliefs concerning what constitute appropriate organizational and daily practices may lead to conflicts and limit the potential for trust to emerge between the parties. The findings also highlight how the success of an acquisition is strictly related to the management of the post-acquisition phase. As today's business decisions and choices are increasingly influenced by the diverse cultural backgrounds and by the perspectives of various corporate stakeholders, it becomes an imperative for managers to acquire multicultural understanding and capabilities. It would be therefore be advisable to develop a development program both for the executives and for the employees. Workshops and cultural initiatives could be established to enable a fuller multicultural appreciation of the mutual differences. Despite the topic gaining importance, research on the internationalization of Chinese MNEs is quite limited to studies that attempt to provide an overall overview of the trends with a limited focus on specific sectors and on the drivers of the acquisitions' choices (Pietrobelli et al., 2010; Amighini et al., 2010). Therefore, this research has contributed to our knowledge by providing evidence related to the strategic drivers behind the acquisition and the main difficulties that can arise during the integration process between the target and the acquirer. The limited number of Chinese acquisitions in Italy in the luxury sector prevents the conduction of a more generalizable econometric assessment. A case study approach has been therefore deemed as an appropriate methodological approach. While this approach can provide in-depth insights, the issue of generalizability looms larger here than with other approaches. The research focused only on two case studies. Conducting additional studies within different sectors of the Made in Italy luxury industry is desirable. Moreover, despite the reliance in the case studies on multiple sources of evidence, it tended to rely more on the views provided respectively by the CFO, who is Italian in the Benelli case and by the CEO, who is Chinese in the OMAS case. This has inevitably led to some bias in the findings and hearing the views from their counterpart would have provided a more faithful representation of the acquisition. However, accessing those actors proved impossible in this research. Nonetheless, given the increasing number of Chinese acquisitions in Italy and their important implications for the luxury industry, this study serves to stimulate further research to generate a cumulative body of knowledge on the topic. This scenario represents a great learning opportunity for both the Italian and the Chinese firms. From the perspectives of not only the target and acquiring firms but also the home and host country economies, it is crucial to gain a full appreciation of how this phenomenon can be transformed into mutually beneficial 
outcomes. Therefore, additional studies may help to reveal further problems arising in the integration process and thus suggest corrective actions that can be implemented to ease the success of the acquisitions. Due to the increasing intensification of Chinese acquisitions activities and of the related fears and expectations regarding Chinese expansion into the luxury Made in Italy sector a fuller understanding of the phenomenon is not only desirable but also indeed necessary. This is critically important given the degree of anxiety that stems from the sensitivity of this novel topic. The provision of concrete research results can assist governments in responding to this phenomenon by adjusting their policies so that local economies are able to capitalise on the advantages to be derived while minimising the negative impacts.

\section{References}

Amighini, A., Rabellotti, R., \& Sanfilippo, M. (2010). The outward FDI from developing country MNEs as a channel for technological catch-up. Working Papers Print 012, Dipartimento Scienze Economiche, Universita' di Bologna.

Barkema, H. G., Bell, J. H., \& Pennings, J. M. E. (1996). Foreign entry, cultural barriers and learning. Strategic Management Journal, 3(1), 151-166.

Burghart, N., \& Rossi, V. (2009). China's overseas direct investment in the UK. Chatham House Programme Paper IE.

Child, J., \& Rodrigues, B. S. (2005). The internationalization of Chinese firms: A case for theoretical extension?. Management and Organization Review, 1(3), 381-410.

Cohen, W. M., \& Levinthal, D. A. (1990). Absorptive capacity: A new perspective on learning and innovation. Administrative Science Quarterly, 35, 128-152.

Cross, A. R., \& Voss, H. (2008). Chinese direct investment in the United Kingdom: An assessment of motivations and competitiveness. Proceedings from Corporate Strategies in the New Asia, University of Bremen.

Dunning, J. H. (1981). Explaining the international direct investment position of countries: Towards a dynamic or developmental approach. WeltwirtschaftlichesArchiv, 119, 30-64.

Dunning, J. H. (2006). Towards a new paradigm of development: Implications for the determinants of international business. Transnational Corporations, 15(1), 173-227.

Dunning, J. H., \& Narula, R. (1996). Foreign direct investment and governments: Catalysts for economic restructuring. London: Routledge.

Filippov, S., \& Saebi, T. (2008). Europeanisation strategy of Chinese companies: Its perils and promises. MERIT Working Papers 055, United Nations University-Maastricht Economic and Social Research Institute on Innovation and Technology (MERIT).

Fortanier, F., \& Van Tulder, R. (2008). Internationalization trajectories - A cross-country comparison: Are large Chinese and Indian companies different?. Retrieved from http://www.merit.unu.edu/publications/wppdf/2008/wp2008-054.pdf

Hofstede, G. (1980). Culture's consequences: International differences in work-related values. London: Sage.

Liu, L., \& Tian, Y. (2008). The internationalisation of Chinese enterprises: The analysis of the UK case. International Journal of Technology and Globalization, 4(1), 87-102.

Mariotti, S., \& Mutinelli, M. (2009). Italia multinazionale 2008: Le partecipazioni italiane all'estero ed estere in Italia (Italia multinazionale 2008: Le partecipazioni italiane all'estero ed estere in Italia). Soveria Mannelli: Rubbettino.

Mathews, J. A. (2002). Dragon Multinationals - A new model for global growth. Oxford: Oxford University Press.

Mathews, J. A. (2006). Dragon multinationals: New players in 21st century globalization. Asia Pacific Journal of Management, 23, 5-27.

MOFCOM. (2011). Statistical bulletin of china's outward foreign direct investment. Retrieved from http://hzs.mofcom.gov.cn/accessory/201109/1316069658609.pdf

Pietrobelli, C., Rabellotti, R., \& Sanfilippo, M. (2010). The "Marco Polo" effect: Chinese FDI in Italy. International Economics Programme Paper, 4.

Rabellotti, R., \& Sanfilippo, M. (2008). Chinese FDI in Italy. Proceedings from the Conference of Emerging Multinationals: Outward Foreign Direct Investment from Emerging and Developing Economies, Copenhagen Business School, Copenhagen.

Rhodium Group. (2012). China invests in Europe. Retrieved from http://rhgroup.net/wp-content/uploads/2012/06/RHG_ChinaInvestsInEurope_June2012.pdf 
Rios-Morales, R., \& Brennan, L. (2010). The emergence of Chinese investment in Europe. EuroMed Journal of Business, 5(2), 215-231.

Rugman, A. M. (1981). Inside the multinationals: The economics of internal markets. New York: Columbia University Press.

Rui, H., \& Yip, G. S. (2008). Foreign acquisitions by Chinese firms: A strategic intent perspective. Journal of World Business, 43(2), 213-226.

Schuller, M., \& Turner, A. (2005). Global ambitions: Chinese companies spread their wings. Journal of Current Chinese Affairs, 34(4), 3-14.

Spigarelli, F., Wei, W., \& Alon, I. (2011). Benelli and QJ compete in the international motorbike arena. Chinese International Investments (pp. 355-371).

Tellis, W. (1997). Application of a case study methodology. The Qualitative Report, 3(3), 1-17.

The Economist. (2012). Luxury on the cheap: Chinese and other buyers snap up Italian brands. Retrieved from http://www.economist.com/node/21550285

UNCTAD. (2011). World investment report: Non-equity modes of international production and development. Retrieved from http://www.unctad-docs.org/files/UNCTAD-WIR2011-Full-en.pdf

Vecchi, A. (2008). Globalisation and the viability of industrial districts. Saarbrucken, Germany: Verlag Dr Muller.

Vecchi, A. (2013). Chinese acquisitions and their impact on the made in Italy luxury sector. Journal of International Finance and Economics, 13(2), 75-82.

Yamin, M., \& Forsgren, M. (2006). Hymer's analysis of the multinational organization: Power retention and the demise of the federative MNE. International Business Review, 15(2), 166-179.

Yin, R. K. (2008). Applications of case study research. Sage: Newbury Park. 